\title{
IMPACT OF OWNERSHIP STRUCTURE ALONG THE VALUE CHAIN IN \\ THE MANUFACTURING BUSINESS
}

\author{
Jan H Scholtz \\ Department of Chemical Engineering, University of Pretoria, Private Bag X20, Hatfield 0028, \\ South Africa
}

\begin{abstract}
In the chemical and petrochemical industry it is quite common that the manufacturing of a final product is the result of several consecutive steps which can be owned and operate by one or many participants. Although not always practical, equal ownership among all partners along the value chain is often recommended as a way to simplify business structure, ensuring all partners share equally in the ups and downs of an uncertain market. In contrast to this approach, there are instances where more benefit can be derived from having different owners and operators along the value chain. Examples which are common practise in the industry are the supply of utilities (e.g. electricity), feedstock and services. In these cases the non-integrated approach offers value as:

It provides the operator of the upstream or utility plants the opportunity to specialize, for example, by operating very similar plants around the world. Such specialization enables the use of regional operating centres, minimum onsite cash costs, optimized operating conditions, minimized energy consumption and the optimal use of other variable cost parameters. This paper shows that if outsourcing results in a cash cost saving by an upstream operator, the benefit to the downstream owner will (in financial reward) be
\end{abstract}


proportional to the cash cost saving achieved. In absolute terms, the magnitude of the benefit is moderated by the size of the downstream capital investment. (The bigger the downstream investment relative to the upstream investment, the smaller the impact of the saving on the economics of the downstream company.)

As a "utility provider" an upstream operator benefits from lower risk in terms of offtake and market price uncertainties. Such owners benefit from a lower cost of capital, and as such also have lower return expectations than players further along in the value chain (who are exposed to all the uncertainties in volatile markets). This paper shows that the positive impact of such benefits to the return of the downstream partner is directly proportional the difference in return expectations between the upstream and downstream company. Once again, the absolute magnitude of the saving becomes more substantial as the ratio of upstream capital investment increases relative to the downstream capital investment.

Economy of learning may also enable a specialized upstream company to obtain an asset at a lower capital than a less specialized downstream operator. This paper shows that the positive impact of such a benefit is very similar to that of a lower return expectation by the upstream company.

\section{Key Words}

Ownership Structure, Vertical Manufacturing, Chemical Engineering, Process Synthesis, Business Structure, Outsourcing 


\section{Introduction}

In the chemical and petrochemical industry it is quite common that the manufacturing of a final product is the result of several consecutive steps which can be owned and operate by one or many participants. For example, crude oil is first recovered from a well. After that it is processed in an oil refinery to petrol, diesel, naphtha, and other products. Naphtha in turn, could be cracked to ethylene, which again finds application in the manufacturing of several synthetic components such as polyethylene.

Although not always practical, equal ownership among all partners along the value chain is often recommended as a way to simplify business structures, ensuring all partners share equally in the ups and downs of an uncertain market. This approach is especially attractive in cases where intermediate products are not traded in the open market, and as such do not have well defined market prices.

In contrast to this approach, there are instances where more benefit can be derived from having different owners and operators along the value chain. Examples which are common practise in the industry are the supply of utilities (such as electricity) and speciality or industrial gases to downstream chemical operations. In these cases the non-integrated approach offers value as:

- It provides the operator of the upstream or utility plant the opportunity to specialize, operating very similar plants around the world. Such specialization enables the use of regional operating centres, minimum onsite cash costs, optimized operating conditions, minimized energy consumptions and benefits in other variable cost parameters. 
- As a "utility provider" these operators often benefit from lower risk in terms of offtake and market price uncertainties. As such, these owners benefit from a lower cost of capital, and often have lower return expectations than players further along in the value chain, which are exposed to all the uncertainties in volatile markets.

The issue of partnering and organizational structure in the petrochemical industry is often central in the development of new production facilities via the execution of a mega construction project. Merrow ${ }^{1}$ highlights that the failure rate of megaprojects is as high as $75 \%$. He identifies a notion of "I want to keep it all!" as one of the key seven mistakes leading to the failure of mega projects ${ }^{1}$. Partnering and financing is as such seen as key aspects to be addressed in scoping such a project ${ }^{1}$.

Many papers have studied the impact of organizational form, in terms of ownership and contractual leverage, on business success. These studies covered various options, from full vertical integration on the one extreme, to complete outsourcing on the other.

Various arguments have been made in favour of outsourcing. Harrigan ${ }^{2}$ identifies that outsourcing can reduce internal costs related to overheads, limits excess capacity in specific manufacturing steps, and support efforts to maintain competitiveness. Elimination or avoidance of intensive capital investments in hardware is identified by Ketler and Walstrom ${ }^{3}$ as a key drive in favour of outsourcing in the Information Management field. Similar arguments (as well as in terms of the cost of capital) can be made for of other industries. Mahoney ${ }^{4}$ identifies benefits related to (i) bureaucratic costs (internal organizations often suffer from more costly manufacturing processes due to the lack of an efficient market mechanism), ii) strategic considerations (in terms of intermediate products, the integrated company has less access to tacit knowledge in the market place, and may lose flexibility 
due to pre-investment in specialized equipment), (iii) production costs (the integrated company may lack economy of scale in specific production lines). Vining and Globerman ${ }^{5}$ support these points, highlighting that the cost of production could be lower as a result of outsourcing because of (i) economy of scale of the manufacturer which develop as a result of outsourcing by several other players. (ii) Efficiency (induced by market forces), (iii) management focus, (iv) elimination of complexities associated with internal manufacturing. All these arguments, in essence, indicate that outsourcing can translate into lower cash costs or a more efficient application of capital. Weidenbaum ${ }^{6}$ highlights that the key focus created within the core company can be strengthened via the appropriate outsourcing of support functions.

Similarly, many arguments in favour of vertical integration have been made. Harrigan ${ }^{2}$ identifies integrated economics (elimination of some intermediate processing steps), improved coordination, elimination of intercompany transactions, improved competitiveness (via better marketing or technology intelligence), and the ability to create product differentiation as advantages associated with integrated manufacturing. Mahoney ${ }^{4}$ furthermore highlights that vertical financial ownership eliminates intercompany transaction costs, argues that vertical integration is favourable from a strategic perspective (e.g. raising barriers to entry), it can be levered to secure output and/or input price advantages, or it can be used as a mechanism to manage cost and/or price uncertainties. These arguments, in essence, suggest that transaction costs related to outsourcing can reduce, or even overshadow the savings associated with outsourcing in terms of cash cost.

Harrigan $^{2}$ points out that many of the benefits of vertical integration can be achieved via a variety of organization structures, not necessarily relying on full ownership of all aspects of the value chain. Harrigan distinguishes among nonintegration (strategies for attaining 
material and markets with no internal transfers and no ownership like contracts), quasiintegration (use of cooperative ventures, minority equity agreements or long term agreements), taper integration (when firms are backward or forward integrated, but rely on outsiders for portions of their supplies or distribution), and full integration. He suggests a decision on the ideal level of integration needs to be made taking into account (i) the breadth of integrated activities, (ii) number of stages of activities, (iii) degree of internal transfers for each vertical linkage, and, (iv) the form of ownership used to control the vertical relationship. These factors need to be considered against the backdrop of the (i) forces propelling industry evolution (ii) nature of competition, (iii) bargaining power of suppliers or distributors, and (iv) corporate strategy. In a later study Harrigan ${ }^{7}$ develops a framework for the use of joint ventures to achieve business goals. It is pointed out that vertical joint ventures find application when demand uncertainty is high yet growing rapidly. Examples of this include the establishment of vertical joint ventures to build infrastructure (which required economy of scale) in the petrochemical industry in the 1940's and 1950's. Horizontal joint ventures, consolidating the industry is more common when growth is slow yet demand uncertainty is high. Vining and Globerman ${ }^{5}$ highlighted that the outsourcing principle is applied very differently by different firms. Some companies outsource the core of their manufacturing, while others outsource secondary activities. It is pointed out that various forms of "outsourcing" as alternative to vertical integration exists. Fundamentally they believe the purpose of outsourcing should be to reduce costs. The authors explain how the outsourcing choice is clearest where both complexity of monitoring and asset specificity are low. When asset specificity becomes high, some form of long term contracting becomes important. Mahoney ${ }^{4}$ concluded that in the absence of agency and transaction costs, vertical financial ownership is equivalent to other forms of vertical 
contracting. Mahoney ${ }^{4}$ proposed, however, as a general theorem that in the absence of agency or transaction costs, every motive for vertical financial ownership can be achieved in an alternative way by an appropriate vertical contract.

In summary, the financial impact links to the impact vertical integration and/or outsourcing has (i) on capital or the cost of capital, (ii) variable costs, (iii) fixed costs, and (iv) the product price. Although these studies explain the relationships qualitatively, it does not provide a method to estimate what the impact of a benefit may have on overall profitability quantitatively.

This paper aims to explore these concepts in the context of the petrochemical industry (although all principles are equally applicable to other manufacturing processes involving multiple steps), aiming to quantify the value of specific advantages linked to outsourcing.

Let us assume that a petrochemical company outsource the manufacturing of its utilities and/or commodity feedstocks to companies that specialize in the production of the latter. As such, these upstream or utility companies can offer products at more competitive prices due to:

- a lower weighted average cost of capital (WACC) and lower return expectations.

- lower capital resulting from economy of learning.

- lower cash costs due to preferential feedstock arrangements and better optimized operating conditions and better structured cash costs.

The benefit of these advantages to a downstream company can be calculated on a case by case basis via a typical numerical or spread sheet economic model. The purpose of this paper is, however, to try and identify the key parameters that will determine the outcome of such a spread sheet model. Furthermore, the importance of the various parameters are 
analysed using a semi analytical approach, predicting the benefit of outsourcing by means of simple correlations. With these correlations, the potential financial impact of key organisational decisions can be bounded, guiding decision makers as to whether the complexity (and transactional costs) associated with such an approach could be worthwhile.

Firstly, a model is developed to describe the interdependency of companies in the production process. Although the model is non-linear in nature, approximation methods as described by Bender and Orszag ${ }^{8}$ are used to find explicit expressions, capturing the impact of the independent variables on profitability. This is an approach commonly followed in Chemical Engineering studies ${ }^{9}$. By using the latter the impact of weighted average cost of capital and return expectations, cash cost benefits, and actual capital costs are studied.

\section{Model}

For the purpose of the study two chemical processes will be considered. (The model is equally valid for any other two consequential manufacturing processes.) The first process results from a capital investment of $c_{1}$ and a yearly cash cost (i.e. variable plus fixed costs) is $f_{1}$. The second process uses the product from the first process (at a cost of $p_{1}$ per annum), delivering the final product which is marketed at a price of $p_{2}$ per year. This is shown schematically in Schematic 1.

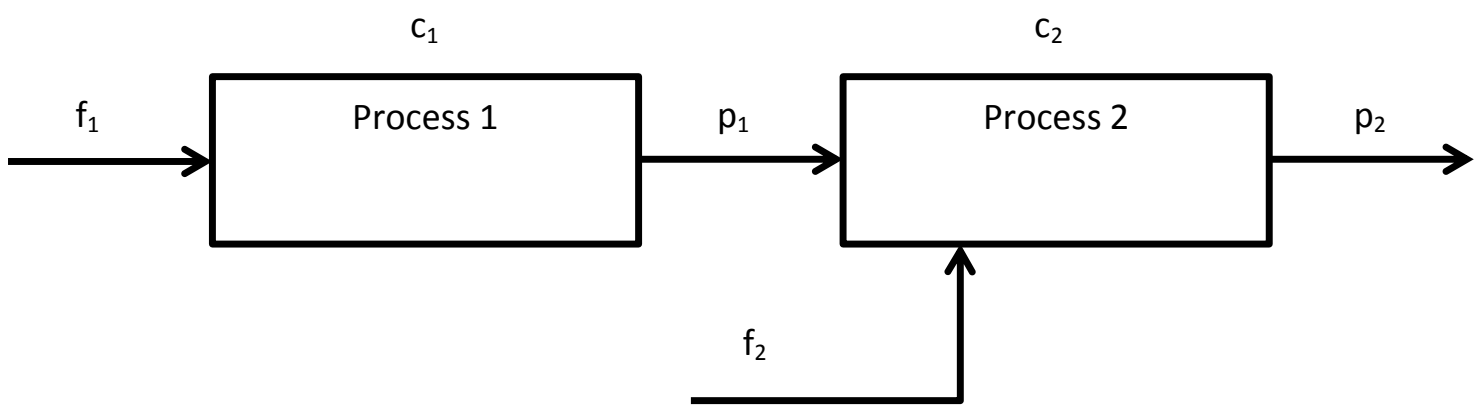

Schematic 1 Representation of sequential activities in a value chain 
The earnings before interest, taxes, depreciation, and amortisation (EBITDA) for each process (i.e. where $\mathrm{i}=1$ or 2 ) can be calculated as follows:

EBITDA $_{i}=p_{i}-f_{i}-p_{(i-1)}$ where

$\mathrm{p}_{\mathrm{i}}$ is the turnover earned from process $\mathrm{i}$ (i.e. annual product quantity produced and sold $\mathrm{X}$ unit price) and $\mathrm{p}_{0}$ is defined as zero (as there is no step preceding Process 1 )

$\mathrm{f}_{\mathrm{i}}$ is the annual cash cost producing the product sold (i.e. annual feedstock used $\mathrm{X}$ unit feedstock cost + fixed cost)

If we further assume that the capital associated with each process (i.e. $\mathrm{c}_{\mathrm{i}}$ ), is depreciated linearly over $m$ years, the earnings before interest, taxes (EBIT) for the first $m$ years of operation, can be calculated as follows:

$\mathrm{EBIT}_{i}=p_{i}-f_{i}-p_{(i-1)}-(1 / m) c_{i}$

Assuming a tax rate of $\mathrm{t}$, and assuming no interests apply, the annual profit can be calculated as:

Profit $_{i}=\left(p_{i}-f_{i}-p_{(i-1)}-(1 / m) c_{i}\right)(1-t)$

or, the actual cash flow each of the first $m$ years can be calculated as:

Cash Flow ${ }_{i}=\left(p_{i}-f_{i}-p_{(i-1)}\right)(1-t)+(1 / m) c_{i} t$

After the first $m$ years, no depreciation applies anymore, and the last term in the latter equation will disappear, i.e.:

Cash Flow ${ }_{i}=\left(p_{i}-f_{i}-p_{(i-1)}\right)(1-t)$ 
If we perform the calculations in real terms, correcting the cost of capital to account for inflation, and assume the real discount rate used by the company owning Process $\mathrm{i}$ is $\mathrm{w}_{\mathrm{i}}$, the net present value for each process in the beginning of the first year can be calculated as:

$\operatorname{NPV}_{\mathrm{i}}=\left(\sum_{n=1}^{\infty}\left(\mathrm{p}_{\mathrm{i}}-\mathrm{f}_{\mathrm{i}}-\mathrm{p}_{(\mathrm{i}-1)}\right)(1-\mathrm{t}) /\left(1+\mathrm{w}_{\mathrm{i}}\right)^{\mathrm{n}}\right)+\left(\sum_{n=1}^{m}(1 / \mathrm{m}) \mathrm{c}_{\mathrm{i}} \mathrm{t} /\left(1+\mathrm{w}_{\mathrm{i}}\right)^{\mathrm{n}}\right)-\mathrm{c}_{\mathrm{i}}$

by assuming the process will be in operation for a very long time and all the capital is spent on the first day of the first year (or the capital is evaluated on an instantaneous job cost basis at the end of year 0 ).

Since the equation is in the form of a geometric series, it can be rewritten as (See Appendix A):

$N P V_{i}=\left(p_{i}-f_{i}-p_{(i-1)}\right)(1-t) / w_{i}+(1 / m) c_{i} t\left[\left(1-1 /\left(1+w_{i}\right)^{m}\right) / w_{i}\right]-c_{i}$

If we now specifically apply the latter relationship to Process $1 \& 2$, the following two equations result:

$N P V_{1}=\left(p_{1}-f_{1}\right)(1-t) / w_{1}+(1 / m) c_{1} t\left[\left(1-1 /\left(1+w_{1}\right)^{m}\right) / w_{1}\right]-c_{1}$

$N P V_{2}=\left(p_{2}-f_{2}-p_{1}\right)(1-t) / w_{2}+(1 / m) c_{2} t\left[\left(1-1 /\left(1+w_{2}\right)^{m}\right) / w_{2}\right]-c_{2}$

In order to compare the importance of the various parameters in these equations, it is beneficial to rewrite the equations in a normalized, dimensionless format. This can be done by introducing the following parameters:

$P_{i}=p_{i} / c_{i}$
$F i=f_{i} / c_{i}$ 
And $\mathrm{C}=\mathrm{c}_{1} / \mathrm{c}_{2}$

Using these parameters, the derived equations can be re-written as:

$N P V_{1} / c_{1}=\left(P_{1}-F_{1}\right)(1-t) / w_{1}+(1 / m) t\left[\left(1-1 /\left(1+w_{1}\right)^{m}\right) / w_{1}\right]-1$

$N P V_{2} / c_{2}=\left(P_{2}-F_{2}-c P_{1}\right)(1-t) / w_{2}+(1 / m) t\left[\left(1-1 /\left(1+w_{2}\right)^{m}\right) / w_{2}\right]-1$

These equations can now be used in various ways:

- Assuming the owner of Process $\mathrm{s}_{\mathrm{i}}$ has access to capital at a weighted average cost of capital (WACC) of $\mathrm{w}_{\mathrm{i}}(100 \%)$, the normalized NPV for this owner at WACC can be calculated by setting $w_{i}$ to match WACC . If a normalized NPV of bigger than zero results, the owner will be able to recover the capital investment, but will not necessarily achieve its desired profit.

- Assuming the owner of Process $\mathrm{i}_{\mathrm{i}}$ has a return expectation of $\mathrm{w}_{\mathrm{i}}(100 \%)$, the normalized NPV for this owner at its desired return can be calculated by setting the discount ratio to match the latter return expectation. If a normalized NPV of equal to or bigger than zero results in these circumstances, the owner will be able to achieve its desired return expectation.

- Finally the unleveraged IRR for Process $s_{i}$ can be derived from the discount rate resulting from the calculation if the normalized NPV is set to zero. If the calculated discount rate is higher than the desired return expectation, the owner will benefit from a higher than necessary IRR to meet its return expectations.

As a result, the relationship among $\mathrm{w}_{\mathrm{i}}, \mathrm{F}_{\mathrm{i}}, \mathrm{P}_{\mathrm{i}}$, and $\mathrm{c}$ in the case where $\mathrm{NPV}_{\mathrm{i}}=0$ is of particular interest. As such, the following special cases where $\mathrm{NPV}_{\mathrm{i}}=0$ were derived: 
In the case where the owner of Process 1 earns an NPV of 0 , the following relationship results:

$P_{1}=F_{1}+w_{1} /(1-t)-((1 / m) t /(1-t))\left(1-1 /\left(1+w_{1}\right)^{m}\right)$

Similarly, if the NPV for Process 2 is set to 0 the following relationship results:

$P_{2}=F_{2}+c P_{1}+w_{2} /(1-t)-((1 / m) t /(1-t))\left(1-1 /\left(1+w_{2}\right)^{m}\right)$

In the case where both processes are owned by the same owner both $w_{1}$ and $w_{2}$ can be set equal to $w$, and the following relationship can be derived from (1) and (2):

$P_{2}=F_{2}+c F_{1}+w(1+c) /(1-t)-(1+c)((1 / m) t /(1-t))\left(1-1 /(1+w)^{m}\right)$

Using these three equations, the economic impact of splitting the ownership of Process 1 and Process 2 will be studied in the rest of this paper.

\section{Different Return Expectations}

The first aspect we wish to analyse in this paper is the case where the upstream Process owner benefits from a lower WACC and a lower return expectation than the owner of the downstream Process. (This is typically the case where the upstream owner is an utility provider, or produce a feedstock suitable for many customers.) This means that the minimum discount rate $\left(w_{1}\right)$ that owner of Process ${ }_{1}$ will require to meets its return expectation is lower than that for the owner of the integrated Process or Process $2(w)$. If, as a result of splitting the ownership of Process ${ }_{1}$ and Process ${ }_{2}, \mathrm{w}_{2}$ for Process 2 turns out to be higher than w (assuming final product price is kept unchanged), the owner of Process 2 will benefit from a higher than required return. As a matter of fact, the premium in IRR can be expressed as $\left(w_{2}-w\right)$. This premium can be calculated by inserting equation (1) 
into equation (2) and setting equation (2) equal to equation (3). In the latter case, the following relationship results:
$\left(w_{2}-w\right)+(1 / m) t\left[\left(1 /\left(1+w_{2}\right)^{m}\right)-\left(1 /(1+w)^{m}\right)\right]=c\left(w-w_{1}\right)+c(1 / m) t\left[\left(1 /(1+w)^{m}\right)-\right.$ $\left.\left(1 /\left(1+w_{1}\right)^{m}\right)\right]$

\section{Special case of zero tax rate}

In the case of a zero tax rate, the non-linearity in equations 4 disappears, resulting in the following equation:

$$
\left(w_{2}-w\right)=c\left(w-w_{1}\right)
$$

From equation 5 it can be seen that in the special case where a zero tax rate applies, the benefit for the owner of Process ${ }_{2}$, to outsource Process ${ }_{1}\left(w_{2}-w\right)$, is directly related to the reduced return expectation of the owner of the outsourced process, Process ${ }_{1}\left(w-w_{1}\right)$, and the magnitude of the benefit is linked to the relative capital intensity of Process ${ }_{1}$.

In order to make this result more illustrative, let's consider an example where a downstream operator needs electricity to operate his plant, and to construct a power station to become self sufficient will require an investment (i.e. $c_{1}$ ) which is $10 \%$ of what he needs to invest for the downstream operations (i.e. $c_{2}$ ), or $c_{1} / c_{2}=0.1$. Furthermore, let's assume a specialized electricity company has a return expectation $2 \%$ lower than that of the specific downstream operator. So the benefit of outsourcing will be calcuated as follows:

$\left(w_{2}-w\right)=c\left(w-w_{1}\right)$ 


$$
\begin{aligned}
& =0.1 \times 2 \% \\
& =0.2 \%
\end{aligned}
$$

So the downstream company can increase its return by $0.2 \%$ via outsourcing.

Stating this in more general terms, when the upstream owner has a lower return expectation than the downstream owner, the return of the downstream partner is directly proportional to the difference in return expectations between the upstream and downstream company. The absolute magnitude of the saving becomes more substantial as the ratio of upstream capital investment increases relative to the downstream capital investment.

\section{Importance of non-linearity when tax is not zero}

Considering that real discount ratios are fractions and relatively small, as a first approximation, the non-linear terms in equation 4 can be approximated by means of a Taylor series as follows:

Let's define a function as $f\left(y_{i}\right)=1 / y_{i}^{m}$

By means of a Taylor expansion we can show that:

$$
\begin{aligned}
f\left(1+x_{i}\right) & \approx f(1)+d f /\left.d y\right|_{y=1}\left(x_{i}\right) \\
& =1-\left.m\left(1 / y_{i}^{(m+1)}\right)\right|_{y=1}\left(x_{i}\right) \\
& =1-m x_{i}
\end{aligned}
$$

If we substitute this relationship into equation (4) the following approximation results: 
$\left(w_{2}-w\right)-(1 / m) t\left[m w_{2}-m w\right]=c\left(w-w_{1}\right)-c(1 / m) t\left[m w-m w_{1}\right]$

$\left(w_{2}-w\right)-t\left(w_{2}-w\right)=c\left(w-w_{1}\right)-c t\left(w-w_{1}\right)$

Which simplifies to the zero tax rate equation, (i.e. equation 5)

$\left(w_{2}-w\right)=c\left(w-w_{1}\right)$

As such, we can anticipate that Equation 5 will be a good approximation over a wide range of discount ratios, even if the tax rate is not zero. In an example which follows at the end of this section it is shown that this simplification is justified even at tax rates as high as $30 \%$.

We can also get to the same equation by noting that depreciation on a capital investment of this nature typically happens over many years (i.e. $m$ is large), in which case equations (1) to (3) simplifies as follows:

$P_{1}=F_{1}+W_{1} /(1-t)$

$P_{2}=F_{2}+c P_{1}+w_{2} /(1-t)$

$\mathrm{P}_{2}=\mathrm{F}_{2}+\mathrm{cF} \mathrm{F}_{1}+\mathrm{w}(1+\mathrm{c}) /(1-\mathrm{t})$

By substituting $\left(1^{\prime}\right)$ into $\left(2^{\prime}\right)$ and equating $\left(2^{\prime}\right)$ to $\left(3^{\prime}\right)$, once again equation (5) results:

$\left(w_{2}-w\right)=c\left(w-w_{1}\right)$

This serves as further explanation why equation (5) seems to hold (as can be seen in Figure 1), or at least directionally gives the right answer (as can be seen in Figure 2 and Figure 3), when the tax is not equal to zero. 


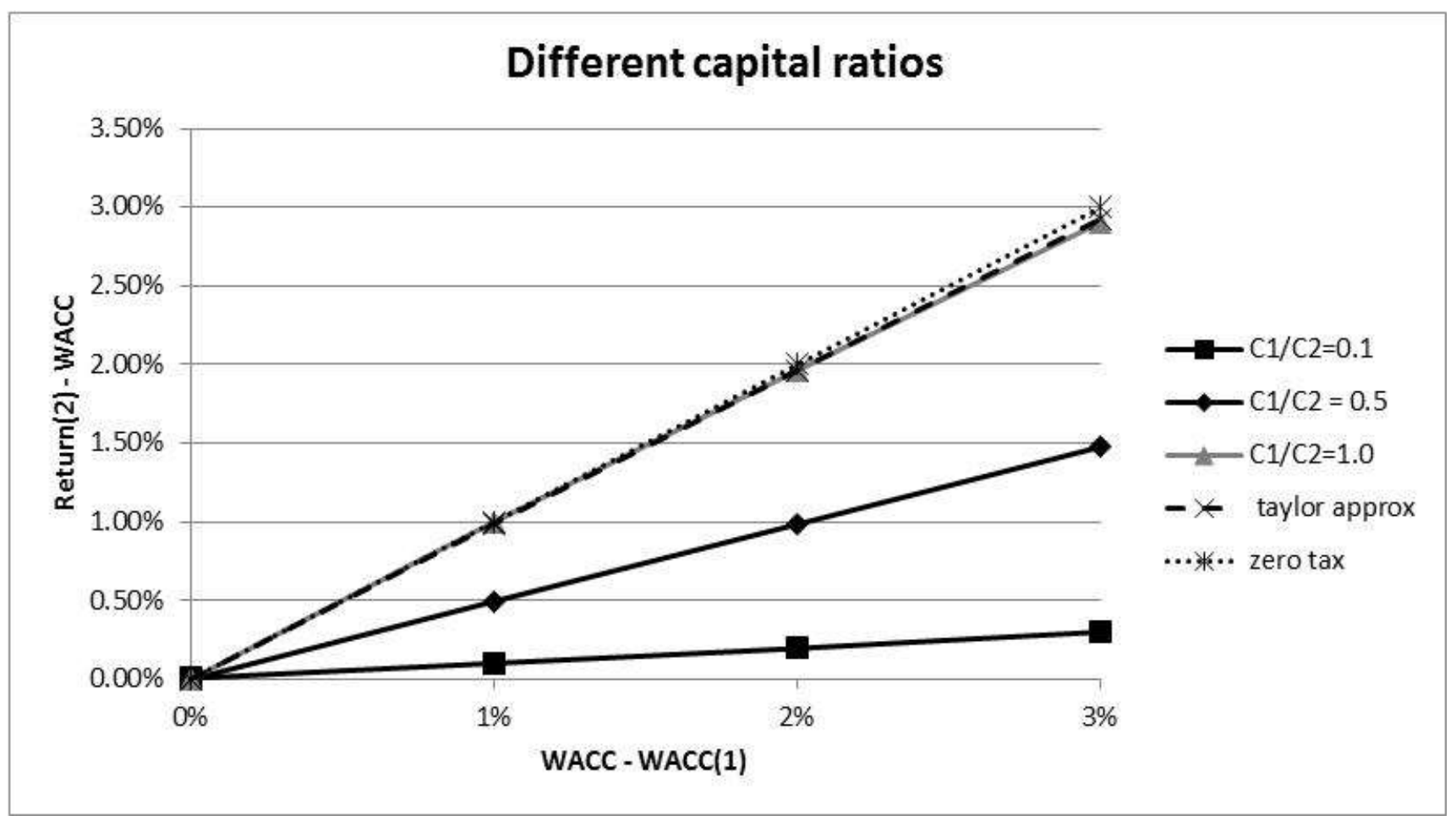

Figure 1: Additional return which can be earned by a downstream company when it uses a higher discount rate than a feedstock or utility company providing an input to its operation. The two approximate solutions (as obtained via a Taylor expansion, or by neglecting tax) is demonstrated for the case where $c_{1} / c_{2}=1.0$.

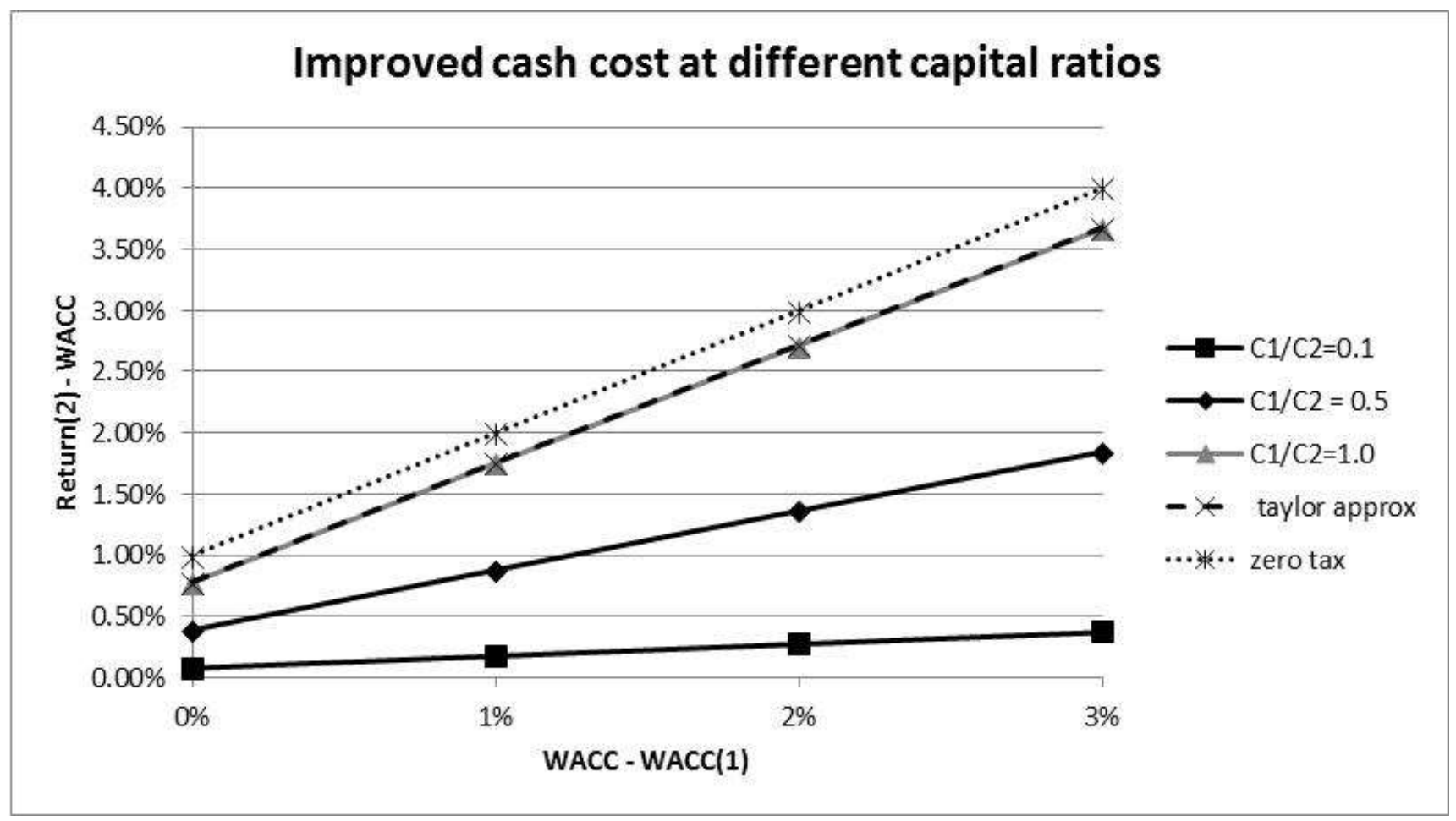

Figure 2: Additional return which can be earned by a downstream company when it levers an upstream company with a more efficient cash cost structure. The two approximate solutions (as obtained via a Taylor expansion, or by neglecting tax) is demonstrated for the case where $c_{1} / c_{2}$ = 1.0. 


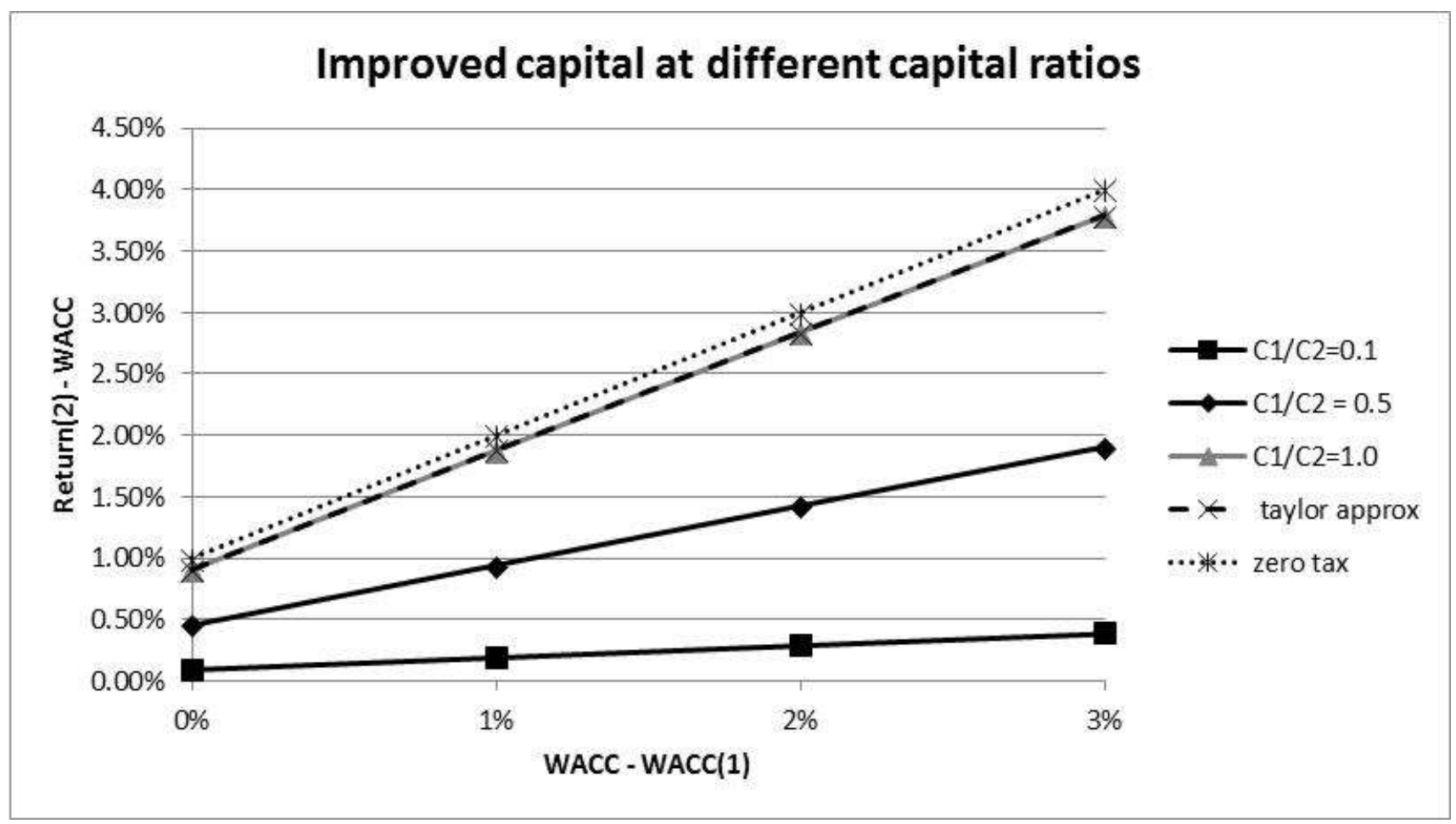

Figure 3: Additional return which can be earned by a downstream company when it levers an upstream company which can benefit from a lower capital investment. The two approximate solutions (as obtained via a Taylor expansion, or by neglecting tax) is demonstrated for the case where $c_{1} / c_{2}=1.0$.

\section{Improving the quality of the approximate answer}

From the previous section it can be deducted that $w_{2}$, the solution to equation (4), is not highly sensitive to the tax rate and as such it can be stated that:

$\mathrm{W}_{2}=\underline{\mathrm{w}}_{2}+\varepsilon$

where $\underline{\underline{w}}_{2}$ is the solution to equation (4) in the special case that the tax rate is zero and $\varepsilon$ is a small quantity, related to the tax rate.

As such:

$$
\begin{aligned}
\left(w_{2}-w\right)= & \left(\underline{w}_{2}+\varepsilon-w\right) \\
& =\left(\underline{w}_{2}-w\right)+\varepsilon
\end{aligned}
$$




$$
=c\left(w-w_{1}\right)+\varepsilon
$$

By substituting the latter relationship in equation (4) and making use of a Taylor series expansion, it is shown in Appendix $C$ that $\varepsilon$ can be approximated with an explicit equation:

$\varepsilon=\left[(t / m)-A\left(1+\underline{w}_{2}\right)^{m}\right] /\left[A m\left(1+\underline{w}_{2}\right)^{m-1}-\left(1+\underline{w}_{2}\right)^{m}\right]$

where

$A=(t / m)\left(1 /(1+w)^{m}\right)+(c t / m)\left[\left(1 /(1+w)^{m}\right)-\left(1 /\left(1+w_{1}\right)^{m}\right)\right]$

The validity of this approximation is demonstrated by means of some numerical examples below, and it predicts the true answer correctly typically to three significant digits.

\section{Numerical examples improved returns for downstream owners}

For the purpose of the example the following parameters where chosen in solving equation 4:

Required return for owner of Process 1 is set at $10 \%$ (i.e. $\mathrm{w}_{1}=10 \%$ )

$\mathrm{t}=30 \%$

$\mathrm{m}=10$ years

The results obtained at four different discount rates for the downstream company is shown in Figure 1 for various capital ratios. According to the zero tax approximation (i.e. Equation 5), a linear relationship with a gradient equal to the capital ratio can be expected. Solving the full equation (Equation 4) results in answers as depicted by the solid lines in Figure 1. The three curves confirm the strong dependency on the capital ratio and the different return expectations of the upstream and downstream companies. It can be seen that a 
linear relationship, as predicted with the zero tax approximation still holds. The solution based on the Taylor expansion around the zero tax solution (i.e. Equation 6), match the true solution very well. This is demonstrated further with Table 1 (comparing results at a value of $\left(w-w_{1}\right)=3 \%$, where deviation among the different solutions are the biggest over the range considered in Figure 1).

Table 1 Accuracy of the approximated equation for selected points on Figure 1

\begin{tabular}{|l|l|l|l|l|}
\hline $\begin{array}{l}\text { Capital Ratio } \\
\left(\mathrm{c}_{1} / \mathrm{c}_{2}\right)\end{array}$ & $\begin{array}{l}\text { Return } \\
\text { expectation } \\
\text { delta } \\
\left(\mathrm{w}-\mathrm{w}_{1}\right)\end{array}$ & $\begin{array}{l}\text { Improved } \\
\text { return (full } \\
\text { calculation) } \\
\left(\mathrm{w}_{2}-\mathrm{w}\right) \\
\text { i.e. Eq } 4\end{array}$ & $\begin{array}{l}\text { Improved return } \\
\text { at zero tax } \\
\left(\mathrm{w}_{2}-\mathrm{w}\right) \\
\text { i.e. Eq 5 }\end{array}$ & $\begin{array}{l}\text { Approximated } \\
\text { Improved } \\
\text { return } \\
\left(\mathrm{w}_{2}-\mathrm{w}\right) \\
\text { i.e. Eq 6 }\end{array}$ \\
\hline 0.1 & $3 \%$ & $0.30 \%$ & $0.30 \%$ & $0.30 \%$ \\
\hline 0.5 & $3 \%$ & $1.48 \%$ & $1.50 \%$ & $1.47 \%$ \\
\hline 1.0 & $3 \%$ & $2.91 \%$ & $3.00 \%$ & $2.93 \%$ \\
\hline
\end{tabular}

This numerical example again demonstrates that outsourcing becomes important when there is a significant difference (i.e. $1 \%$ or more) between the return expectation of an upstream and downstream company, and the capital for the upstream investment is significant relative to the downstream investment (possibly more than at least $5 \%$ ).

From Table 1 it can be seen that since $\varepsilon$ is very small, even with tax neglected an excellent approximation to the original implicit equation can be obtained. This means that in terms of a delta in return expectation between upstream and downstream companies, financial impact can be estimated merely by knowing the delta in return expectations and the capital ratio between the two processes.

\section{Impact of operating efficiency on the benefit of outsourcing}

In terms of equation (1), let us say that if the cash cost to operate Process ${ }_{1}$ by the integrated company is $f_{1}$, and the specialised company can reduce the latter cost to a 
fraction of that (i.e. $b_{1}$ ). In the latter case, equation (1) needs to be modified as per equation (1a) if it is operated and owned by a specialist company:

$P_{1}=b F_{1}+w_{1} /(1-t)-((1 / m) t /(1-t))\left(1-1 /\left(1+w_{1}\right)^{m}\right)$

While the required turnover for owner of Process 2 remains at

$P_{2}=F_{2}+c P_{1}+w_{2} /(1-t)-((1 / m) t /(1-t))\left(1-1 /\left(1+w_{2}\right)^{m}\right)$

Therefore, if the two processes are owned by different owners, the turnover for Process 2 is calculated by inserting (1a) into (2):

$P_{2}=F_{2}+c b F_{1}+c w_{1} /(1-t)-c((1 / m) t /(1-t))\left(1-1 /\left(1+w_{1}\right)^{m}\right)+w_{2} /(1-t)-((1 / m) t /(1-t))(1-$ $\left.1 /\left(1+w_{2}\right)^{m}\right)$

In the case where both processes are owned by the same owner, the integrated operation equation stays unchanged:

$P_{2}=F_{2}+c F_{1}+w(1+c) /(1-t)-(1+c)((1 / m) t /(1-t))\left(1-1 /(1+w)^{m}\right)$

If we equate the two equations (i.e. assume the product price is kept the same, regardless of whether the first step is outsourced or not):

$\left(w_{2}-w\right)+(1 / m) t\left[1 /\left(1+w_{2}\right)^{m}-1 /(1+w)^{m}\right]=c\left(w-w_{1}\right)+(1-t)(1-b) c F_{1}+c(1 / m) t\left[1 /(1+w)^{m}-\right.$ $\left.1 /\left(1+w_{1}\right)^{m}\right]$

This again, can be approximated as:

$$
\begin{aligned}
\left(w_{2}-w\right)= & \left(\underline{w}_{2}+\varepsilon-w\right) \\
& =\left(\underline{w}_{2}-w\right)+\varepsilon \\
& =c\left(w-w_{1}\right)+(1-b) c F_{1}+\varepsilon
\end{aligned}
$$


Where once again

$\varepsilon=\left[(t / m)-A\left(1+\underline{w_{2}}\right)^{m}\right] /\left[A m\left(1+\underline{w_{2}}\right)^{m-1}-\left(1+\underline{w_{2}}\right)^{m}\right]$

while $A$ is slightly modified

$A=(1 / m) t\left(1 /(1+w)^{m}\right)-t(1-b) c F_{1}+c(1 / m) t\left[\left(1 /(1+w)^{m}\right)-\left(1 /\left(1+w_{1}\right)^{m}\right)\right]$

This, if the tax rate is zero, can be simplified to:

$\left(\underline{w}_{2}-w\right)=c\left(w-w_{1}\right)+(1-b) c F_{1}$

As such, we can anticipate that an improved cash cost will improve the return with (1-b)cF $F_{1}$ if the effect of tax can be neglected.

In order to elucidate the concepts captured in Equation 7b, lets revisit our earlier example where a downstream operator needs electricity to operate his plant, and to construct a power station to become self sufficient will require an additional investment of $10 \%$ relative to what he needs to invest for the rest of his operations. Again, let's assume a specialized electricity company has a return expectation $2 \%$ lower than that of the specific downstream operator. In this case, however, we assume that the specialized electricity provider will have a cash cost advantage of $15 \%$ over the downstream operator in terms of the manufacturing of electricity (i.e. $b=0.85$ ). Furthermore, the yearly cash cost of making electricity is $5 \%$ of the original upstream capital.

So the benefit of outsourcing will be calculated as follows:

$$
\begin{aligned}
\left(w_{2}-w\right) & =c\left(w-w_{1}\right)+(1-b) c F_{1} \\
= & 0.1 \times 2 \%+0.15 \times 0.1 \times 5 \%
\end{aligned}
$$




$$
=0.2 \%+0.075 \%=0.275 \%
$$

So in more general terms, the cash cost advantage resulted in an additional benefit for the downstream company. The additional benefit to the downstream owner is proportional to the cash cost saving achieved. In absolute terms, the magnitude of the benefit is moderated by the size of the downstream capital investment. (The bigger the downstream investment relative to the upstream investment, the smaller the impact of the saving on the economics of the downstream company.)

In more general terms, using the numerical example depicted in Figure 1 as a basis, taking $F_{1}$ as 0.1 , and reducing the cash cost for a speciality operator of Process ${ }_{1}$ by $10 \%$ (i.e. $b=0.9$ ), impacts the results as shown in Figure 2 . For comparative purposes the results were once again calculated with the complete and approximate relationships for the case where $c_{1 /} c_{2}=1$.

From the results it can be seen that although the approximated equation (Equation 7 a) still provides an accurate answer, the effect of tax can no longer be ignored. Neglecting tax is persistently overestimating the benefit. (Nevertheless, directionally the impact is still the same, even if the magnitude is wrong.) From Table 2 (where $\mathrm{c} 1 / \mathrm{c} 2=1$, and all other parameters are as per the numerical example with the exception of $t$ and $b$ ) it appears as if

Table 2 Accuracy of the approximated equation at different operating efficiencies and tax rates

\begin{tabular}{|l|l|l|l|l|l|l|}
\hline $\begin{array}{l}\text { Operating } \\
\text { Efficiency } \\
(b)\end{array}$ & $\begin{array}{l}\text { Tax Rate } \\
(\mathrm{t})\end{array}$ & $\begin{array}{l}\text { Improved } \\
\text { return } \\
\left(\mathrm{w}_{2}-\mathrm{w}\right) \\
\mathrm{Eq} 7(\mathrm{a})\end{array}$ & $\begin{array}{l}\text { Improved } \\
\text { return } \\
\text { ignoring tax } \\
\left(\mathrm{w}_{2}-\mathrm{w}\right) \\
\mathrm{Eq} 7(\mathrm{~b})\end{array}$ & $\begin{array}{l}\text { Delta } \\
\left(\mathrm{w}_{2}-\mathrm{w}\right)- \\
\left(\underline{\mathrm{w}}_{2}-\mathrm{w}\right)\end{array}$ & $\begin{array}{l}\text { Delta } \\
\text { relative to } \\
\text { operating } \\
\text { efficiency }\end{array}$ & $\begin{array}{l}\text { Delta } \\
\text { relative to } \\
\text { tax }\end{array}$ \\
\hline 100 & 30 & 2.93 & 3.00 & 0.07 & \} 0.26 & \\
\hline 90 & 30 & 3.67 & 4.00 & 0.33 & \} 0.26 & \} \\
\hline 80 & 30 & 4.41 & 5.00 & 0.59 & 30 \\
\hline 80 & 15 & 4.71 & 5.00 & 0.29 & & \} 0.29 \\
\hline 80 & 0 & 5.00 & 5.00 & 0.00 & & \} \\
\hline
\end{tabular}


the overestimation is proportional to $\mathrm{t}(1-\mathrm{b})$, which suggest that as a first approximation $\varepsilon \approx$ $\mathrm{t}(1-b) F_{1}$.

In general we can say that a cash cost improvement alters the intercept of the $y$ axis of Figure 2. The more pronounced the cash cost benefit of the specialized upstream operator, the bigger the impact on the $y$ intercept.

\section{Impact of capital efficiency on the benefit of outsourcing}

Let's consider the case where the capital for Process $s_{1}$ would have been $c_{1}$ if an integrated company would have invested in it. Let's now further assume that when a specialist company invest in the same process (i.e. Process ${ }_{1}$ ) the capital can be reduced to a fraction of $c_{1}$ (i.e. $\mathrm{dc}_{1}$ ) by taking advantage of economy of learning. In such a case, if Process $\mathrm{s}_{1}$ is operated and owned by a specialist company, the governing equations (1-3) have to be modified as follows:

$\mathrm{p}_{1} / \mathrm{c}_{1}=\mathrm{f}_{1} / \mathrm{c}_{1}+\mathrm{dw}_{1} /(1-\mathrm{t})-((1 / \mathrm{m}) \mathrm{dt} /(1-\mathrm{t}))\left(1-1 /\left(1+\mathrm{w}_{1}\right)^{\mathrm{m}}\right)$

(note, $P_{1}$ still is defined as $p_{1} / c_{1}$, even though the true capital in the case of a speciality company is $\mathrm{dc}_{1}$ )

Similarly, the required turnover for owner of Process 2 would be

$P_{2}=F_{2}+p_{1} / c_{2}+w_{2} /(1-t)-((1 / m) t /(1-t))\left(1-1 /\left(1+w_{2}\right)^{m}\right)$

Which expands to:

$P_{2}=F_{2}+f_{1} / c_{2}+(d c) w_{1} /(1-t)-(d c)((1 / m) t /(1-t))\left(1-1 /\left(1+w_{1}\right)^{m}\right)+w_{2} /(1-t)-$ $((1 / m) t /(1-t))\left(1-1 /\left(1+w_{2}\right)^{m}\right)$ 
If Equation (1b) is inserted into Equation (2)

In the case where both processes are owned by the same owner, equation 3 applies as before,

$\mathrm{w}=\mathrm{w}_{1}=\mathrm{w}_{2}$ and

$P_{2}=F_{2}+c F_{1}+w(1+c) /(1-t)-(1+c)((1 / m) t /(1-t))\left(1-1 /(1+w)^{m}\right)$

By equating the latter two equations it can be shown (Appendix B) that:

$\left(w_{2}-w\right)+(1 / m) t\left[1 /\left(1+w_{2}\right)^{m}-1 /(1+w)^{m}\right]=c\left(w-d w_{1}\right)+c(1 / m) t\left[(d-1)+1 /(1+w)^{m}\right.$ $\left.-d /\left(1+w_{1}\right)^{m}\right]$

This can once again be approximated as:

$$
\begin{aligned}
\left(w_{2}-w\right)= & \left(\underline{w}_{2}+\varepsilon-w\right) \\
& =\left(\underline{w}_{2}-w\right)+\varepsilon \\
& =c\left(w-d w_{1}\right)+\varepsilon
\end{aligned}
$$

Where once again

$\varepsilon=\left[(t / m)-A\left(1+\underline{w_{2}}\right)^{m}\right] /\left[A m\left(1+\underline{w_{2}}\right)^{m-1}-\left(1+\underline{w_{2}}\right)^{m}\right]$

while $A$ is modified to

$A=(1 / m) t\left(1 /(1+w)^{m}\right)+c(1 / m) t\left[(d-1)+\left(1 /(1+w)^{m}\right)-\left(d /\left(1+w_{1}\right)^{m}\right)\right]$

This, if the tax rate is zero, simplified to:

$\left(\underline{w}_{2}-w\right)=c\left(w-d w_{1}\right)$ 
If we compare Equation $8 \mathrm{~b}$ with Equation 5 , we can see that in the absence of tax the impact of a lower return expectation by a specialist company is equivalent to that of a better capital efficiency. For example, if in real terms, the down stream company has a return expectation of $10 \%$ then the impact of an upstream owner with a return expectation of $1 \%$ lower, or a capital efficiency of $10 \%$ higher (i.e. $d=0.9$ ) would be similar.

Numerical results were generated once more using the reference example, as used for Figure 1, as a basis. However, it is assumed that the capital invested by a speciality operator of Process ${ }_{1}$ will be $10 \%$ (i.e. $d=0.9$ ) less of what an integrated company would have invested in a similar process. The results as shown in Figure 3, were generated using both the complete and approximate relationships.

From the results it can be seen that the approximated equation provides the right answer. The impact of tax (at a material level of $30 \%$ ) is once again visible, however directionally Equation 8 b still captures the correct behaviour.

Based on the observation we have made in terms of Equation $8 \mathrm{~b}$ above, we would anticipate that a $10 \%$ additional capital efficiency by a specialized company (as used in this example), will result in a benefit equivalent to a $1 \%$ lower return expectation by the specialist company. If we compare the results as shown in Figure 1 with that in Figure 3 we can see that this general rule holds quite well.

\section{General Relationship}

In cases where all three principles come into play (capital efficiency, operating efficiency, and reward expectations) the following general relationship will apply: 
$\left(w_{2}-w\right)+(1 / m) t\left[1 /\left(1+w_{2}\right)^{m}-1 /(1+w)^{m}\right]=c\left(w-d w_{1}\right)+(1-t)(1-b) c F_{1}+$

$c(1 / m) t\left[(d-1)+1 /(1+w)^{m}-d /\left(1+w_{1}\right)^{m}\right]$

As shown in appendix $D$, this can be approximated as:

$$
\begin{aligned}
\left(w_{2}-w\right)= & \left(\underline{w}_{2}+\varepsilon-w\right) \\
& =\left(\underline{w}_{2}-w\right)+\varepsilon \\
& =c\left(w-d w_{1}\right)+(1-b) c F_{1}+\varepsilon
\end{aligned}
$$

Where once again

$\varepsilon=\left[(t / m)-A\left(1+\underline{w}_{2}\right)^{m}\right] /\left[A m\left(1+\underline{w}_{2}\right)^{m-1}-\left(1+\underline{w}_{2}\right)^{m}\right]$

while $A$ is modified to

$A=(1 / m) t\left(1 /(1+w)^{m}\right)-t(1-b) c F_{1}+c(1 / m) t\left[(d-1)+\left(1 /(1+w)^{m}\right)-\left(d /\left(1+w_{1}\right)^{m}\right)\right]$

This, if the tax rate is zero, simplified to:

$\left(\underline{w}_{2}-w\right)=c\left(w-d w_{1}\right)+(1-b) c F_{1}$

If we apply the empiric tax correction, $\varepsilon=-\mathrm{t}(1-\mathrm{b}) \mathrm{cF}_{1}$ (as it immerged when we studied the impact of different cash costs only), we have an alternative approximate equation:

$$
\left(w_{2}-w\right)=c\left(w-d w_{1}\right)+(1-b) c F_{1}-t(1-b) c F_{1}
$$




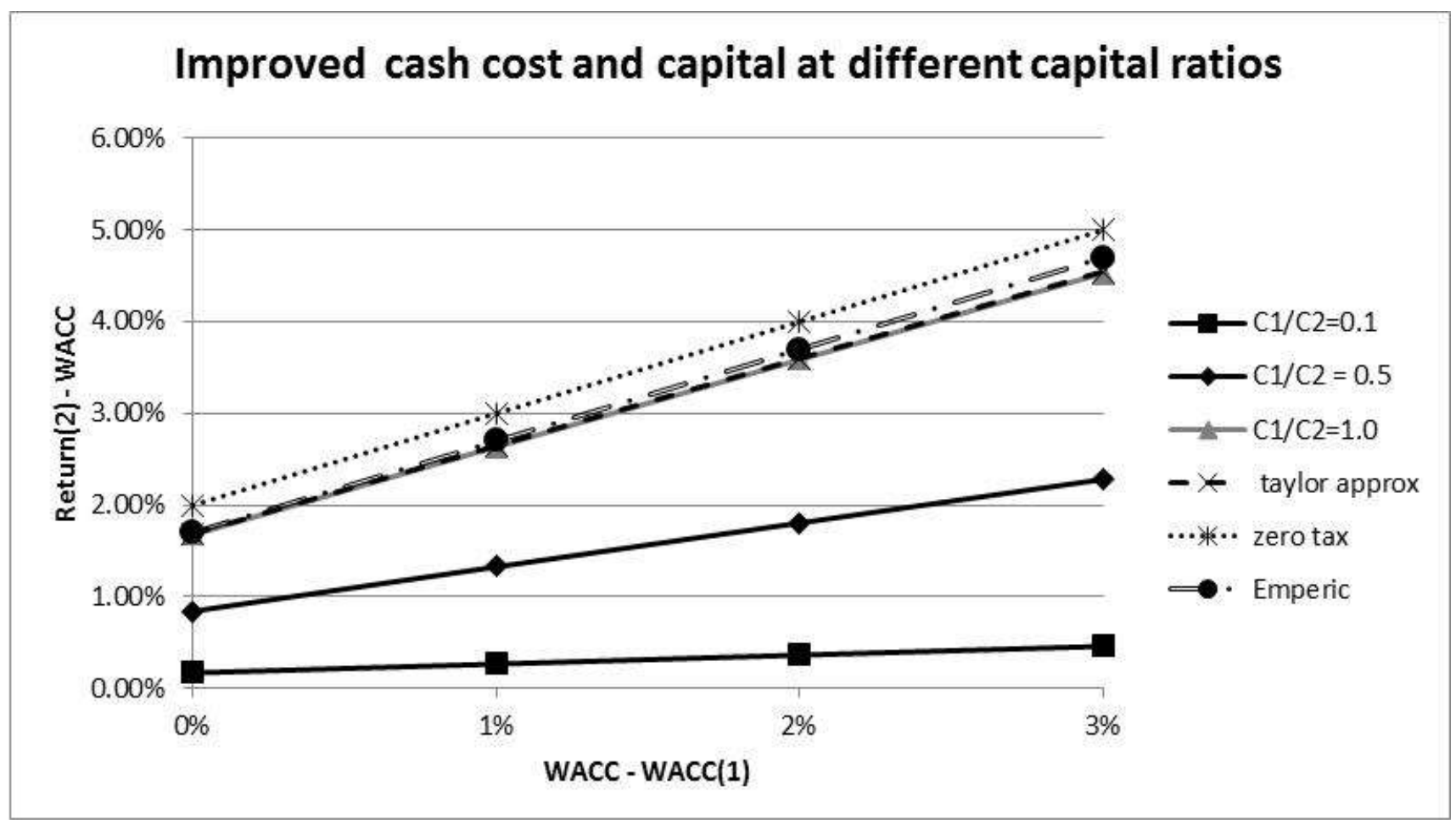

Figure 4: Additional return which can be earned by a downstream company when it levers an upstream company which can benefit from improved cash cost position and a lower capital investment. The three approximate solutions (as obtained via a Taylor expansion, by neglecting tax, or using an empiric correlation for $\varepsilon$ ) is demonstrated for the case where $c_{1} / c_{2}=1.0$.

Results from 9a, 9b, and 9c, relative to solving the full implicit equation (9) for the return premium are shown in Figure 4 for the case where:

$F_{1}=0.1$

Required return for owner of Process 1 of $10 \%$ (i.e. $\mathrm{w}_{1}=10 \%$ )

$$
t \quad=30 \%, b=90 \%, d=90 \%, m=10
$$

The results in Figure 4 confirm the additive and semi linear nature of the concepts discussed in this paper. The high accuracy that can be obtained via a taylor series approximation is reconfirmed again. More work will be required to get a better 
understanding of the usefulness of the empiric approximation depitched in the graph. As before, neglecting tax at does not impact on the directional behaviour of the relationships derived, but accuracy is much lower at high tax rates such as in this example (where the tax rate is $30 \%)$.

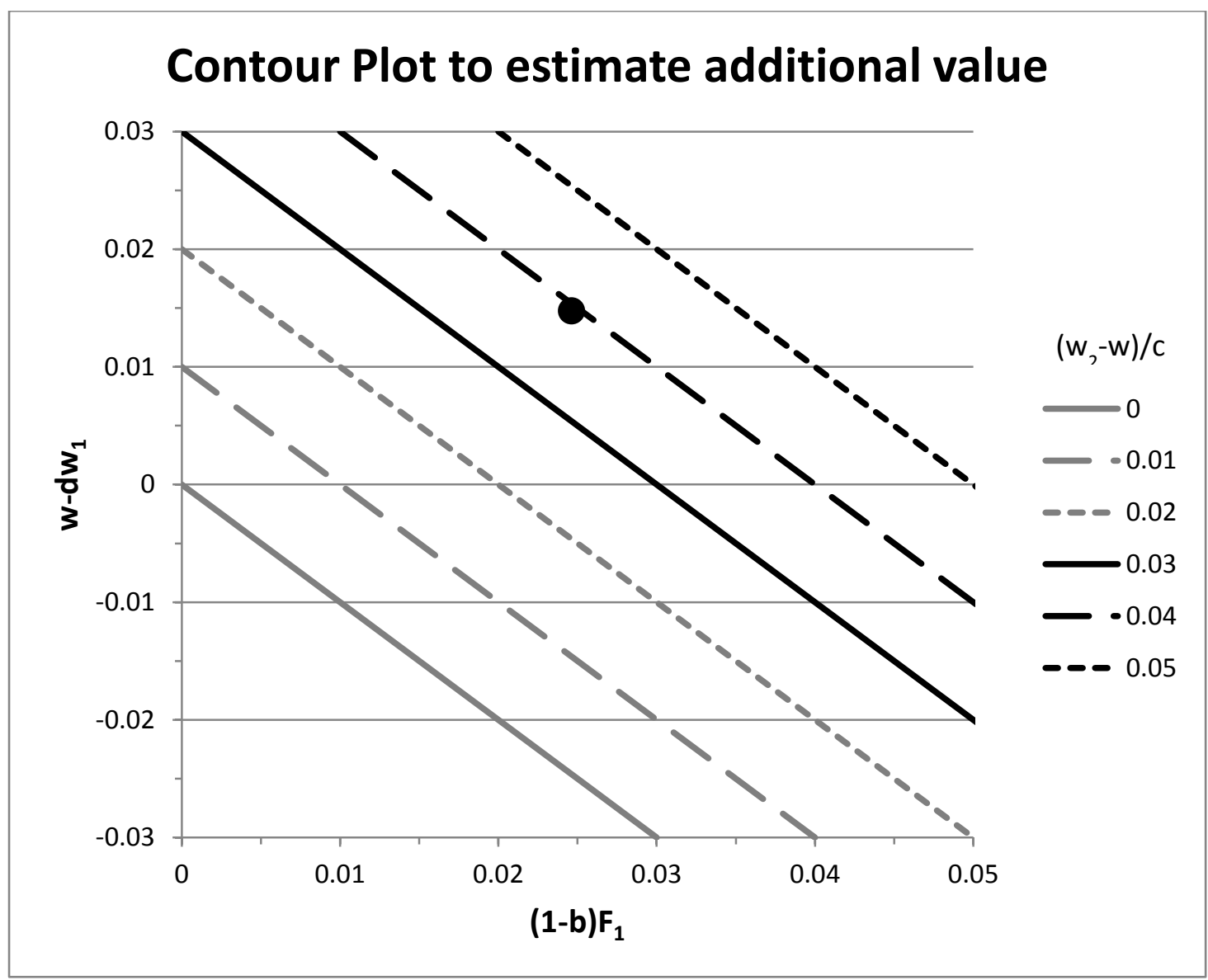

Figure 5: Contour plot to estimate additional return which can be earned by a downstream company when it levers an upstream company which can benefit from an improved cash cost position and a lower capital investment and capital return requirement

In the case of zero tax the interplay among the different influences can also be demonstrated on a contour map as shown in Figure 5. Although the contour map can not provide results as accurate as the taylor series approximation of the fundamental relationships, it captures the directional behaviour in a useful visual way. 
The use of the contour map is demonstrated for the following example by means of the red dotted lines on Figure 5:

Assume a final product is manufactured in two steps (an upstream and a downstream step). The downstream owner can either invest in all the capital, or can outsource the upstream section to a company which specialize in the latter step. The upstream company has a targeted return of $10 \%$ (i.e. $\mathrm{w}_{1}=0.1$ ), and the downstream company has a targeted return of $11 \%$ (i.e. $w=0.11$ ), and it is assumed that the downstream company can set the final product price to achieve the latter return. Furthermore, due to specialization, when the upstream company makes an investment, its capital requirement will only be $95 \%$ of that the downstream company would have to invest in a similar upstream operation (i.e. $d$ $=0.95)$. The upstream company will also save $5 \%$ in cash cost relative to the downstream company in terms of operating and managing the upstream step (i.e. $b=0.95$ ). If the downstream company would have invested in the complete process, it would have invested 1 billon US\$ in the upstream section (i.e. $c_{1}=1 \times 10^{9}$ US\$), 1.5 billion US\$ in the downstream section (i.e. $c_{2}=1.5 \times 10^{9}$ US $\$$ ). It is also estimated that the cash cost it would have spent on the upstream section is 0.5 billion US $\$ / a$ (i.e. $f_{1}=0.5 \times 10^{9}$ US $\$ / a$ ).

For this example

$F_{1}=f_{1} / c_{1}=0.5 \times 10^{9} / 1 \times 10^{9}=0.5$

$c=c_{1} / c_{2}=1 \times 10^{9} / 1.5 \times 10^{9}=0.67$

$(1-b) * F_{1}=(1-0.95) 0.5=0.025$ (i.e. the intersect of the $X$-axis in Figure 5)

$\mathrm{w}-\mathrm{dw}_{1}=0.11-0.95 \times 0.10=0.015$ (i.e. the intersect of the $\mathrm{Y}$-axis in Figure 5) 
By marking these points on the $x$ and $y$ axis of Figure 5 , it can be read from the contours that $\left(w_{2}-w\right) / c=0.039$.

As such, $\mathrm{w}_{2}-\mathrm{w}=0.039 * 0.67=2.61 \%$

As such, the downstream company can increase its return by $2.61 \%$ (assuming it keeps everything else, including product price exactly the same).

So, in general, outsourcing will become financially more attractive as we move towards the right top of the contour plot. In contrary to that, moving towards the left bottom, crossing the $\left(w_{2}-w\right) / c$ line, will result in value being destroyed when an approach of outsourcing is used.

In cases where tax is indeed zero, Figure 5 will provide accurate results. When tax is not zero, Figure 5 can still be used as a first approximation which can then be further refined by means of Equation $9(a)$.

\section{Conclusions}

In the chemical and petrochemical industry it is quite common that the manufacturing of a final product is the result of several consequential steps which can be owned and operate by one or many participants. This paper focuses on the situation where different owners and operators exist along the value chain. The paper analyses cases where the nonintegrated approach offers value as:

- An upstream "utility" provider might benefit from a lower weighted average cost of capital (WACC) which in turn can lead to lower return expectations. 
- A specialist may benefit from lower capital when investing in a similar asset as vertical player by taking advantage from economy of learning.

- Economy of scale may bring lower cash costs due to preferential feedstock arrangements, optimized operating conditions, and efficiently structured cash costs.

The paper shows that the value of outsourcing (taking advantage of the latter opportunities) to the downstream operator can be calculated with the following implicit equation:

$$
\begin{aligned}
& \left(w_{2}-w\right)+(1 / m) t\left[1 /\left(1+w_{2}\right)^{m}-1 /(1+w)^{m}\right]=c\left(w-d w_{1}\right)+(1-t)(1-b) c F_{1}+c(1 / m) t[(d-1) \\
& \left.+1 /(1+w)^{m}-d /\left(1+w_{1}\right)^{m}\right]
\end{aligned}
$$

By means of a Taylor expansion, the latter equation can be approximated as:

$$
\left(w_{2}-w\right)=c\left(w-d w_{1}\right)+(1-b) c F_{1}+\varepsilon
$$

Where

$$
\begin{aligned}
& \varepsilon=\left[(t / m)-A\left(1+\underline{w}_{2}\right)^{m}\right] /\left[A m\left(1+\underline{w_{2}}\right)^{m-1}-\left(1+\underline{w}_{2}\right)^{m}\right] \\
& A=(1 / m) t\left(1 /(1+w)^{m}\right)-t(1-b) c F_{1}+c(1 / m) t\left[(d-1)+\left(1 /(1+w)^{m}\right)-\left(d /\left(1+w_{1}\right)^{m}\right)\right]
\end{aligned}
$$

And $\underline{w}_{2}$, the expected return for the downstream company if no tax applies is defined as:

$$
\left(\underline{w_{2}}-w\right)=c\left(w-d w_{1}\right)+(1-b) c F_{1}
$$

By analysing Equation (9a), assuming $\varepsilon$ is small (as demonstrated with numerical examples in the paper) it can be concluded that: 
- When the operator of the upstream or utility plants succeeds in lowering its cash cost, and pass that benefit on to the downstream operator, the benefit to the latter can be approximated (if the tax rate is low) as:

$$
\left(w_{2}-w\right) \approx(1-b) c F_{1},
$$

This can also be written as:

$$
\Delta \mathrm{w} \approx(1-\mathrm{b}) \mathrm{f}_{1} / \mathrm{c}_{2}
$$

Where:

$\Delta \mathrm{w} \quad$ is the improvement in return for the downstream owner

(1-b) the fractional improvement in the cash cost $\left(f_{1}\right)$ of upstream process

C is the capital of the downstream process

In more general terms, a cash cost advantage by a specialized upstream company can result in an additional benefit for a downstream company levering the benefit via outsourcing. The additional benefit to the downstream company is proportional to the cash cost saving achieved. In absolute terms, the magnitude of the benefit is moderated by the size of the downstream capital investment. (The bigger the downstream investment relative to the upstream investment, the smaller the impact of the saving on the economics of the downstream company.)

- If the upstream operator benefits from a lower cost of capital and associated with that is willing to accept a lower rate of return than the downstream operator, the value to the downstream operator can be estimated as:

$$
\left(w_{2}-w\right)=c\left(w-w_{1}\right)
$$


This can also be written as

$$
\Delta \mathrm{W} \approx \mathrm{c} \Delta \mathrm{W}
$$

Where:

$\underline{\mathrm{w}} \quad$ difference in return expectation for the downstream and upstream owners c ratio of capital of the upstream process divided by the downstream process

The latter equations seem to be accurate over a wide range of tax rates.

Expressing this conclusion in more general terms, when an upstream owner has a lower return expectation than the downstream owner, the return of the downstream partner is directly proportional to the difference in return expectations between the upstream and downstream company. The absolute magnitude of the saving becomes more substantial as the ratio of upstream capital investment increases relative to the downstream capital investment.

- A lower cost of capital for the upstream company can also result from economy of learning, resulting in an actually lower capital cost. This paper shows that the positive impact of such benefits (at low tax rates) can be estimated as:

$$
\left(w_{2}-w\right)=c\left(w-d w_{1}\right)
$$

This equation is very similar to the previous equation, except that the return expectation of the upstream company is modified with a fraction equal to the discounted capital divided by the undiscounted capital. 


\section{Notation}

b

Cash cost efficiency of a specialist (upstream) company relative to the downstream company for an upstream process, i.e. $b=$ (cash cost of upstream process anticipated by upstream specialist)/ (cash cost of upstream process anticipated if operated by downstream owner)

$\mathrm{C}_{\mathrm{i}}$ Capital for process $\mathrm{i}$ (where $\mathrm{i}=1$ for the upstream process, and $\mathrm{i}=2$ for the downstream process)

C Normalized dimensionless value $c_{1} / c_{2}$

d Capital efficiency of a specialist (upstream) company relative to the downstream company for an upstream process, i.e. $d=$ (capital for upstream process anticipated by upstream specialist)/ (capital for upstream process anticipated if investment is designed/developed/implemented by downstream owner)

EBITDA $_{i} \quad$ Earnings before interest, tax, depreciation and amortisation for process $\mathrm{i}$ (where $\mathrm{i}=1$ for the upstream process, and $\mathrm{i}=2$ for the downstream process)

$\varepsilon$

Difference between $w_{2}$ and $\underline{w}_{2}$ (i.e. $w_{2}=\underline{w}_{2}+\varepsilon$ )

$f_{i}$ Yearly cash cost (i.e. variable plus fixed costs) for process i (where i $=1$ for the upstream process, and $\mathrm{i}=2$ for the downstream process)

$\mathrm{F}_{\mathrm{i}} \quad$ Normalized value $\mathrm{f}_{\mathrm{i}} / \mathrm{c}_{\mathrm{i}}$

$\mathrm{m}$ Number of years over which straight line depreciation takes place $\mathrm{NPV}_{\mathrm{i}} \quad$ Net present value for process $\mathrm{i}$ (where $\mathrm{i}=1$ for the upstream 
process, and $\mathrm{i}=2$ for the downstream process)

$\mathrm{p}_{\mathrm{i}}$

Annual market (or transfer) price for the product (i.e. unit price $\mathrm{X}$

volume) from process $\mathrm{i}$ (where $\mathrm{i}=1$ for the upstream process, and $\mathrm{i}$

$=2$ for the downstream process)

$\mathrm{P}_{\mathrm{i}} \quad$ Normalized value $\mathrm{p}_{\mathrm{i}} / \mathrm{c}_{\mathrm{i}}$

t tax rate

$\mathrm{w}_{1} \quad$ Real return requirements by the upstream company to achieve a specific goal (i.e. its discount rate to achieve its targeted return )

W

Real return requirements by the downstream company to achieve a specific goal assuming it invests in the integrated process - that is upstream and downstream (i.e. its discount rate to achieve its targeted return)

$\mathrm{W}_{2}$ Real return for the downstream company (required or achievable) if it only invests in the downstream process.

$\underline{\mathrm{w}_{2}}$ $\mathrm{W}_{2}$ as it would result in a zero tax environment (i.e. if $t=0$ )

\section{Literature Cited}

1. Merrow EW. Industrial megaprojects. John Wiley \& Sons, Inc., Hoboken, New Jersey, 2011.

2. Harrigan KR. Formulating vertical integration strategies. Academy of Management Review. 1984;9(4):638-652.

3. Ketler $\mathrm{K}$, and Walstrom $\mathrm{J}$. The outsourcing decision. International Journal of Information Management. 1993;13:449-459. 
4. Mahoney JT. The choice of organizational form: vertical financial ownership versus other methods of vertical integration. Strategic Management Journal. 1992;13(8):559-584.

5. Vining A, Globerman S. A conceptual framework for understanding the outsourcing decision. European Management Journal. 1999;17(6):645-654.

6. Weidenbaum M. Outsourcing: pros and cons. Business Horizons. 2005;48:311-315.

7. Harrigan KR. Joint ventures and competitive strategy. Strategy Management Journal. $1988 ; 9: 141-158$

8. Bender CM, Orszag SA. Advanced mathematical methods for scientists and engineers. McGraw-Hill, Inc, New York, 1978:61-68.

9. Glasser D, Katz S, Shinnar R. The measurement and interpretation of contact time distribution for catalytic reactor charactirization. Industrial \& Engineering Chemistry Fundamentals. 1973;12(2):165-173. 


\section{Appendix A}

This appendix demonstrates the use of geometric series principles to simplify the governing equations in this paper.

$N P V_{i}=\left(\sum_{n=1}^{\infty}\left(p_{i}-f_{i}-p_{(i-1)}\right)(1-t) /\left(1+w_{i}\right)^{n}\right)+\left(\sum_{n=1}^{m}(1 / m) c_{i} t /\left(1+w_{i}\right)^{n}\right)-c_{i}$

$N P V_{i}=\left(p_{i}-f_{i}-p_{(i-1)}\right)(1-t)\left(\sum_{n=1}^{\infty} 1 /\left(1+w_{i}\right)^{n}\right)+(1 / m) c_{i} t\left(\sum_{n=1}^{m} 1 /\left(1+w_{i}\right)^{n}\right)-c_{i}$

if $\mathrm{S}=\left(\sum_{n=1}^{M} 1 /\left(1+\mathrm{w}_{\mathrm{i}}\right)^{\mathrm{n}}\right)$

then

$\mathrm{S} /\left(1+\mathrm{W}_{\mathrm{i}}\right)=\left(\sum_{n=2}^{M+1} 1 /\left(1+\mathrm{w}_{\mathrm{i}}\right)^{\mathrm{n}}\right)$

and

$\mathrm{S}-\mathrm{S} /\left(1+\mathrm{w}_{\mathrm{i}}\right)=\left(\sum_{n=1}^{M} 1 /\left(1+\mathrm{w}_{\mathrm{i}}\right)^{\mathrm{n}}\right)-\left(\sum_{n=2}^{M+1} 1 /\left(1+\mathrm{w}_{\mathrm{i}}\right)^{\mathrm{n}}\right)$

$S\left(1-1 /\left(1+w_{i}\right)\right)=1 /\left(1+w_{i}\right)-1 /\left(1+w_{i}\right)^{M+1}$

$S=\left[1 /\left(1+w_{i}\right)-1 /\left(1+w_{i}\right)^{M+1}\right] /\left[1-1 /\left(1+w_{i}\right)\right]$

$S=\left[1-1 /\left(1+w_{i}\right)^{M}\right] / w_{i}$

Where, if $M$ is $\infty$ or very large

$\mathrm{S}=1 / \mathrm{w}_{\mathrm{i}}$ (which applies to the first geometric series in the equation to calculate NPV)

and if $M=m$

$\mathrm{S}=\left[1-1 /\left(1+\mathrm{w}_{\mathrm{i}}\right)^{\mathrm{m}}\right] / \mathrm{w}_{\mathrm{i}}$ (which applies to the second geometric series in the equation to calculate NPV) 
Substituting back in the NPV relationship results in:

$N P V_{i}=\left(p_{i}-f_{i}-p_{(i-1)}\right)(1-t)\left(1 / w_{i}\right)+(1 / m) c_{i} t\left(1-1 /\left(1+w_{i}\right)^{m}\right) / w_{i}-c_{i}$

\section{Appendix B}

If we consider the case were $c_{1}$ reduces to a fraction of its value (i.e. $d c_{1}$ ) if it is operated and owned by a specialist company, the governing equations ( $1 b, 2$ and 3 from the main text) are modified as follows:

$p_{1} / c_{1}=f_{1} / c_{1}+d w_{1} /(1-t)-d((1 / m) t /(1-t))\left(1-1 /\left(1+w_{1}\right)^{m}\right)$

Similarly, the required turnover for owner of Process 2 would be

$P_{2}=F_{2}+p_{1} / c_{2}+w_{2} /(1-t)-((1 / m) t /(1-t))\left(1-1 /\left(1+w_{2}\right)^{m}\right)$

Which expands to

$P_{2}=F_{2}+f_{1} / c_{2}+(d c)\left(w_{1} /(1-t)-(d c)((1 / m) t /(1-t))\left(1-1 /\left(1+w_{1}\right)^{m}\right)\right)+w_{2} /(1-t)-$ $((1 / m) t /(1-t))\left(1-1 /\left(1+w_{2}\right)^{m}\right)$

In the case where both processes are owned by the same owner,

$\mathrm{w}=\mathrm{w}_{1}=\mathrm{w}_{2}$ and

$P_{2}=F_{2}+c F_{1}+w(1+c) /(1-t)-(1+c)((1 / m) t /(1-t))\left(1-1 /(1+w)^{m}\right)$

Equating the latter two equations:

$F_{2}+f_{1} / c_{2}+(d c) w_{1} /(1-t)-(d c)((1 / m) t /(1-t))\left(1-1 /\left(1+w_{1}\right)^{m}\right)+w_{2} /(1-t)-((1 / m) t /(1-t))(1-$ $\left.1 /\left(1+w_{2}\right)^{m}\right)=$ 
$\mathrm{F}_{2}+\mathrm{cF}_{1}+\mathrm{w}(1+\mathrm{c}) /(1-\mathrm{t})-(1+\mathrm{c})((1 / \mathrm{m}) \mathrm{t} /(1-\mathrm{t}))\left(1-1 /(1+\mathrm{w})^{\mathrm{m}}\right)$

Simplify as follows:

$(d c) w_{1} /(1-t)-(d c)((1 / m) t /(1-t))\left(1-1 /\left(1+w_{1}\right)^{m}\right)+w_{2} /(1-t)-((1 / m) t /(1-t))\left(1-1 /\left(1+w_{2}\right)^{m}\right)=$ $w(1+c) /(1-t)-(1+c)((1 / m) t /(1-t))\left(1-1 /(1+w)^{m}\right)$

$(d c) w_{1} /(1-t)-(d c)((1 / m) t /(1-t))\left(1-1 /\left(1+w_{1}\right)^{m}\right)+w_{2} /(1-t)-((1 / m) t /(1-t))\left(1-1 /\left(1+w_{2}\right)^{m}\right)=$ $w /(1-t)+w c /(1-t)-((1 / m) t /(1-t))\left(1-1 /(1+w)^{m}\right)-c((1 / m) t /(1-t))\left(1-1 /(1+w)^{m}\right)$

$\mathrm{w}_{2} /(1-\mathrm{t})-\mathrm{w} /(1-\mathrm{t})-((1 / \mathrm{m}) \mathrm{t} /(1-\mathrm{t}))\left(1-1 /\left(1+\mathrm{w}_{2}\right)^{\mathrm{m}}\right)+((1 / \mathrm{m}) \mathrm{t} /(1-\mathrm{t}))\left(1-1 /(1+\mathrm{w})^{\mathrm{m}}\right)=$ $w c /(1-t)-d c w_{1} /(1-t)-c((1 / m) t /(1-t))\left(1-1 /(1+w)^{m}\right)+d c((1 / m) t /(1-t))\left(1-1 /\left(1+w_{1}\right)^{m}\right)$

$\left(w_{2}-w\right) /(1-t)+((1 / m) t /(1-t))\left[1 /\left(1+w_{2}\right)^{m}-1 /(1+w)^{m}\right]=$ $c\left(w-d w_{1}\right) /(1-t)-((1 / m) t /(1-t)) c\left[\left(1-1 /(1+w)^{m}\right)-d\left(1-1 /\left(1+w_{1}\right)^{m}\right)\right]$

$\left(w_{2}-w\right) /(1-t)+((1 / m) t /(1-t))\left[1 /\left(1+w_{2}\right)^{m}-1 /(1+w)^{m}\right]=$ $c\left(w-d w_{1}\right) /(1-t)+c((1 / m) t /(1-t))\left[(d-1)+1 /(1+w)^{m}-d /\left(1+w_{1}\right)^{m}\right]$ 


$$
\begin{aligned}
& \left(w_{2}-w\right)+(1 / m) t\left[1 /\left(1+w_{2}\right)^{m}-1 /(1+w)^{m}\right]=c\left(w-d w_{1}\right)+c(1 / m) t[(d-1)+ \\
& \left.1 /(1+w)^{m}-d /\left(1+w_{1}\right)^{m}\right]
\end{aligned}
$$

\section{Appendix C}

Taylor series expansion around the zero tax rate solution from equation 4 in the main text:

$$
\begin{aligned}
& F\left(w, w_{1}, w_{2}, t\right)=0=\left(w_{2}-w\right)+(1 / m) t\left[\left(1 /\left(1+w_{2}\right)^{m}\right)-\left(1 /(1+w)^{m}\right)\right]-c\left(w-w_{1}\right)- \\
& c(1 / m) t\left[\left(1 /(1+w)^{m}\right)-\left(1 /\left(1+w_{1}\right)^{m}\right)\right] \\
& F\left(w, w_{1}, \underline{w_{2}}, 0\right)=0=\left(\underline{w}_{2}-w\right)-c\left(w-w_{1}\right)
\end{aligned}
$$

If $\mathrm{w}_{2}=\underline{\mathrm{w}}_{2}+\varepsilon$ then Equation $\mathrm{C} 1-$ Equation $\mathrm{C} 2$ can be rewritten as:

$0=\left[\left(w_{2}-w\right)-\left(\underline{w}_{2}-w\right)\right]+(1 / m) t\left[\left(1 /\left(1+w_{2}\right)^{m}\right)-\left(1 /(1+w)^{m}\right)\right]-\left[c\left(w-w_{1}\right)-c\left(w-w_{1}\right)\right]$

$-c(1 / m) t\left[\left(1 /(1+w)^{m}\right)-\left(1 /\left(1+w_{1}\right)^{m}\right)\right]$

$0=\varepsilon+(1 / m) t\left[\left(1 /\left(1+\underline{w}_{2}+\varepsilon\right)^{m}\right)-\left(1 /(1+w)^{m}\right)\right]-c(1 / m) t\left[\left(1 /(1+w)^{m}\right)-\left(1 /\left(1+w_{1}\right)^{m}\right)\right]$

$0=\varepsilon+(1 / m) t\left(1 /\left(1+\underline{w}_{2}+\varepsilon\right)^{m}\right)-(1 / m) t\left(1 /(1+w)^{m}\right)-c(1 / m) t\left[\left(1 /(1+w)^{m}\right)-\right.$

$\left.\left(1 /\left(1+w_{1}\right)^{m}\right)\right]$

If $A=(t / m)\left(1 /(1+w)^{m}\right)+(c t / m)\left[\left(1 /(1+w)^{m}\right)-\left(1 /\left(1+w_{1}\right)^{m}\right)\right]$

Then

$\varepsilon+(1 / \mathrm{m}) \mathrm{t}\left(1 /\left(1+\underline{\mathrm{w}_{2}}+\varepsilon\right)^{\mathrm{m}}\right)=A$

or

$\left(1+\underline{w_{2}}+\varepsilon\right)^{m}=1 /((m / t)(A-\varepsilon))$ 
Using a Taylor series expansion:

$$
\begin{aligned}
F(\varepsilon)= & \left(1+\underline{w_{2}}+\varepsilon\right)^{m} \\
& =F(0)+\left(d F /\left.d \varepsilon\right|_{\varepsilon=0}\right) \varepsilon \\
& =\left(1+\underline{w_{2}}\right)^{m}+(m)\left(1+\underline{w_{2}}\right)^{m-1} \varepsilon \\
& =\left(1+\underline{w_{2}}\right)^{m}\left(1+(\varepsilon m) /\left(1+\underline{w_{2}}\right)\right)
\end{aligned}
$$

Resulting in:

$$
\begin{aligned}
& \left(1+\underline{w_{2}}\right)^{m}+(m)\left(1+\underline{w_{2}}\right)^{m-1} \varepsilon=1 /((m / t)(A-\varepsilon)) \\
& (A-\varepsilon)\left(1+\underline{w_{2}}\right)^{m}+(A-\varepsilon)(m)\left(1+\underline{w_{2}}\right)^{m-1} \varepsilon=1 /(m / t) \\
& A\left(1+\underline{w_{2}}\right)^{m}-\varepsilon\left(1+\underline{w_{2}}\right)^{m}+A(m)\left(1+\underline{w_{2}}\right)^{m-1} \varepsilon-(m)\left(1+\underline{w_{2}}\right)^{m-1} \varepsilon^{z}=1 /(m / t) \\
& {\left[A m\left(1+\underline{w_{2}}\right)^{m-1}-\left(1+\underline{w_{2}}\right)^{m}\right] \varepsilon=(t / m)-A\left(1+\underline{w_{2}}\right)^{m}} \\
& \varepsilon=\left[(t / m)-A\left(1+\underline{w_{2}}\right)^{m}\right] /\left[A m\left(1+\underline{w_{2}}\right)^{m-1}-\left(1+\underline{w_{2}}\right)^{m}\right]
\end{aligned}
$$

\section{Appendix D}

Taylor series expansion around the zero tax rate solution for the general solution

$$
\begin{array}{ll}
F\left(w_{1} w_{1}, w_{2}, t\right)=0=\left(w_{2}-w\right)+(1 / m) t\left[\left(1 /\left(1+w_{2}\right)^{m}\right)-\left(1 /(1+w)^{m}\right)\right]-c\left(w-d w_{1}\right)- & \\
(1-t)(1-b) c F_{1}-c(1 / m) t\left[(d-1)+\left(1 /(1+w)^{m}\right)-\left(d /\left(1+w_{1}\right)^{m}\right)\right] & D 1 \\
F\left(w_{1} w_{1}, \underline{w}_{2}, 0\right)=0=\left(\underline{w}_{2}-w\right)-c\left(w-d w_{1}\right)-(1-b) c F_{1} & D 2 \\
\text { If } \mathrm{w}_{2}=\underline{w_{2}}+\varepsilon \text { then Equation D1 - Equation D2 can be rewritten as: }
\end{array}
$$


$0=\left[\left(w_{2}-w\right)-\left(\underline{w}_{2}-w\right)\right]+(1 / m) t\left[\left(1 /\left(1+w_{2}\right)^{m}\right)-\left(1 /(1+w)^{m}\right)\right]-\left[c\left(w-d w_{1}\right)-c\left(w-d w_{1}\right)\right]$

- $(1-t)(1-b) c F_{1}+(1-b) c F_{1}-c(1 / m) t\left[(d-1)+\left(1 /(1+w)^{m}\right)-\left(d /\left(1+w_{1}\right)^{m}\right)\right]$

$0=\varepsilon+(1 / m) t\left[\left(1 /\left(1+\underline{w_{2}}+\varepsilon\right)^{m}\right)-\left(1 /(1+w)^{m}\right)\right]+t(1-b) c F_{1}-c(1 / m) t\left[(d-1)+\left(1 /(1+w)^{m}\right)\right.$

$\left.-\left(d /\left(1+w_{1}\right)^{m}\right)\right]$

$0=\varepsilon+(1 / m) t\left(1 /\left(1+\underline{w}_{2}+\varepsilon\right)^{m}\right)-(1 / m) t\left(1 /(1+w)^{m}\right)+t(1-b) c F_{1}-c(1 / m) t[(d-1)+$ $\left.\left(1 /(1+w)^{m}\right)-\left(d /\left(1+w_{1}\right)^{m}\right)\right]$

If $A=(1 / m) t\left(1 /(1+w)^{m}\right)-t(1-b) c F_{1}+c(1 / m) t\left[(d-1)+\left(1 /(1+w)^{m}\right)-\left(d /\left(1+w_{1}\right)^{m}\right)\right]$

Then

$\varepsilon+(1 / m) t\left(1 /\left(1+\underline{w}_{2}+\varepsilon\right)^{m}\right)=A$, or

$\left(1+\underline{w}_{2}+\varepsilon\right)^{m}=1 /((m / t)(A-\varepsilon))$

Using a Taylor series expansion:

$$
\begin{aligned}
F(\varepsilon)= & \left(1+\underline{w}_{2}+\varepsilon\right)^{\mathrm{m}} \\
& =F(0)+\left(\mathrm{dF} /\left.\mathrm{d} \varepsilon\right|_{\varepsilon=0}\right) \varepsilon \\
& =\left(1+\underline{\mathrm{w}_{2}}\right)^{\mathrm{m}}+(\mathrm{m})\left(1+\underline{\mathrm{w}_{2}}\right)^{\mathrm{m}-1} \varepsilon \\
& =\left(1+\underline{\mathrm{w}_{2}}\right)^{\mathrm{m}}\left(1+(\varepsilon \mathrm{m}) /\left(1+\underline{\mathrm{w}}_{2}\right)\right)
\end{aligned}
$$

Resulting in:

$$
\begin{aligned}
& \left(1+\underline{w_{2}}\right)^{m}+(m)\left(1+\underline{w_{2}}\right)^{m-1} \varepsilon=1 /((m / t)(A-\varepsilon)) \\
& (A-\varepsilon)\left(1+\underline{w_{2}}\right)^{m}+(A-\varepsilon)(m)\left(1+\underline{w_{2}}\right)^{m-1} \varepsilon=1 /(m / t) \\
& A\left(1+\underline{w_{2}}\right)^{m}-\varepsilon\left(1+\underline{w_{2}}\right)^{m}+A(m)\left(1+\underline{w_{2}}\right)^{m-1} \varepsilon-(m)\left(1+\underline{w_{z}}\right)^{m-1} \varepsilon^{z}=1 /(m / t)
\end{aligned}
$$




$$
\begin{aligned}
& {\left[A m\left(1+\underline{w_{2}}\right)^{m-1}-\left(1+\underline{w_{2}}\right)^{m}\right] \varepsilon=(t / m)-A\left(1+\underline{w_{2}}\right)^{m}} \\
& \varepsilon=\left[(t / m)-A\left(1+\underline{w_{2}}\right)^{m}\right] /\left[A m\left(1+\underline{w_{2}}\right)^{m-1}-\left(1+\underline{w_{2}}\right)^{m}\right]
\end{aligned}
$$

\section{Appendix E}

Special Case: $\mathrm{w}_{1}=\mathrm{w}$

$$
\begin{aligned}
& \begin{aligned}
A & =(1 / m) t\left(1 /(1+w)^{m}\right)-t(1-b) c F_{1}+c(1 / m) t\left[(d-1)+\left(1 /(1+w)^{m}\right)-\left(d /\left(1+w_{1}\right)^{m}\right)\right] \\
& =(t / m)\left(1 /\left(1+w_{1}\right)^{m}\right)-t(1-b) c F_{1}+c(1 / m) t(d-1)+(c t / m)\left(1 /\left(1+w_{1}\right)^{m}\right)-
\end{aligned} \\
& (c t d / m)\left(1 /\left(1+w_{1}\right)^{m}\right) \\
& \quad=t\left[((1+c-c d) / m)\left(1 /\left(1+w_{1}\right)^{m}\right)-(1-b) c F_{1}+c(1 / m)(d-1)\right] \\
&
\end{aligned}
$$

and

$$
\begin{aligned}
\varepsilon & =\left[(t / m)-A\left(1+\underline{w}_{2}\right)^{m}\right] /\left[A m\left(1+\underline{w}_{2}\right)^{m-1}-\left(1+\underline{w}_{2}\right)^{m}\right] \\
& \approx\left[(t / m)-A\left(1+\underline{w}_{2}\right)^{m}\right] /\left[-\left(1+\underline{w}_{2}\right)^{m}\right] \\
& \approx A-(t / m) /\left(1+\underline{w}_{2}\right)^{m}
\end{aligned}
$$

